\title{
Reconstrução da Região Labial Inferior: Um Exemplo de Versatilidade do Retalho Nasogeniano
}

Ermelindo Tavares

Assistente Hospitalar de Dermatologia e Venereologia

Serviço de Dermatologia e Venereologia, Hospital Vila Franca de Xira, Vila Franca de Xira, Portugal

RESUMO - O retalho nasogeniano de pedículo inferior representa uma opção válida e bem reconhecida para reconstrução de defeitos do lábio inferior, tal como no caso que descrevemos.

Homem, 82 anos, com carcinoma basocelular do 1/3 direito da pele do lábio inferior, sem envolvimento da mucosa. Sob anestesia local, a lesão foi excisada com margem cirúrgica adequada, tendo-se gerado um defeito elipsoide complexo. Procedeu-se ao encerramento do mesmo com retalho nasogeniano de pedículo inferior. Não houve necrose no pós-operatório tardio. Os resultados estéticos e funcionais foram aceitáveis.

PALAVRAS-CHAVE - Carcinoma Basocelular; Lábio/cirurgia; Nariz/cirurgia; Procedimentos Cirúrgicos Dermatológicos; RetaIhos Cirúrgicos.

\section{Reconstruction of the Lower Lip Region: An Example of Versatility of Naso-Labial Flap}

ABSTRACT - The nasolabial flap represents a valid and well known option to reconstruct defects of the lower lip as in the following case.

An 82-year-old male patient with a basal cell carcinoma located on the right lower lip skin had a surgical excision under local anesthesia. The large surgical defect was closed with an inferiorly based pedicle nasolabial flap, with no flap necrosis and acceptable functional and aesthetic results.

KEYWORDS - Carcinoma, Basal Cell; Dermatologic Surgical Procedures; Lip/surgery; Nose/surgery; Surgical Flaps.

\section{INTRODUÇÃO}

O tratamento cirúrgico de neoplasias cutâneas malignas (maioritariamente não melanoma) que envolvem o lábio e a região perioral acarreta, por vezes, limitação estética, funcional e social ao doente. Os defeitos cirúrgicos nestas áreas podem ser encerrados directamente ou recorrendo aos retaIhos cutâneos locais, regionais ou, menos frequentemente, à distância. $O$ retalho nasogeniano (NG), após modificações e aperfeiçoamentos, permite reconstruir defeitos labiais superiores e inferiores e da comissura, com preservação de três objectivos fundamentais: segurança, função e estética. ${ }^{1-3}$

\section{CASO CLÍNIICO}

Homem de 82 anos, caucasiano, fototipo II, agricultor reformado, com carcinoma basocelular (CBC) ulcerado, com 2,5 x 1,8 cm, confirmado por biópsia cutânea, envolvendo a região direita da pele do lábio inferior e sem extensão à mucosa labial. A evolução era desconhecida (Fig. 1).

Apresentaçóes e Prémios: Apresentado como Poster, $5^{\circ}$ Curso de Cirurgia e Cosmética Dermatológica, Coimbra 13 e 14 de Outubro de 2017

Correspondência: Ermelindo Tavares Serviço de Dermatologia e Venereologia, Hospital Vila Franca de Xira

Estrada Carlos Lima Costa $n^{\circ} 2$, Povos 2600-009 Vila Franca de Xira, Portugal

Fax: +351263006636

Email: tavares.ermelindo@gmail.com

DOI: https://dx.doi.org/10.29021/spdv.76.1.833
Recebido/Received

19 Outubro/October 2017

Aceite/Accepted

09 Janeiro/January 2018 


\section{Pérolas Cirúrgicas}

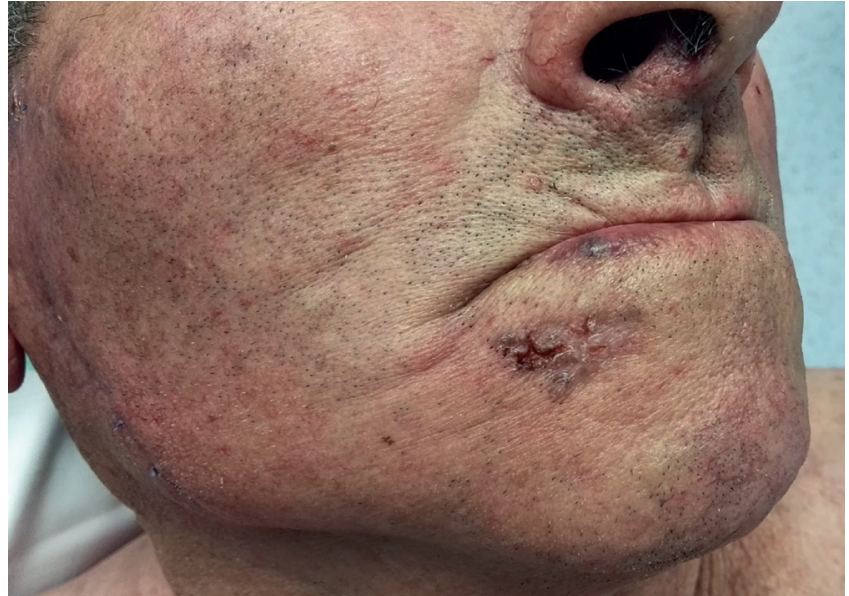

Figura 1 - Placa infiltrada e ulcerada no 1/3 direito da pele do lábio inferior.

A lesão foi excisada sob anestesia local com margem cirúrgica lateral de $5 \mathrm{~mm}$ e profunda englobando tecido adiposo subcutâneo até ao músculo orbicular oral. Gerou-se um defeito elipsoide com $35 \times 28$ mm (Fig. 2). Procedeu-se ao seu encerramento com retalho NG obtido após três planos de incisão e dissecação: lateral externo (região malar), lateral interno (sulco NG) e profundo (tecido adiposo subcutâneo). A sua geometria era triangular, media cerca de $70 \mathrm{~mm}$ de comprimento máximo e o pedículo inferior tinha cerca de $25 \mathrm{~mm}$ de largura (Fig. 2). O mesmo foi transposto, adaptado e integrado no defeito labial (Fig. 3). A zona dadora foi encerrada directamente. Observou-se isquemia transitória de curta duração no pós-operatório imediato (Fig. 3) e hematoma no pós-operatório tardio. Não ocorreu infecção, necrose ou deiscência da sutura operatória ou outra complicação.

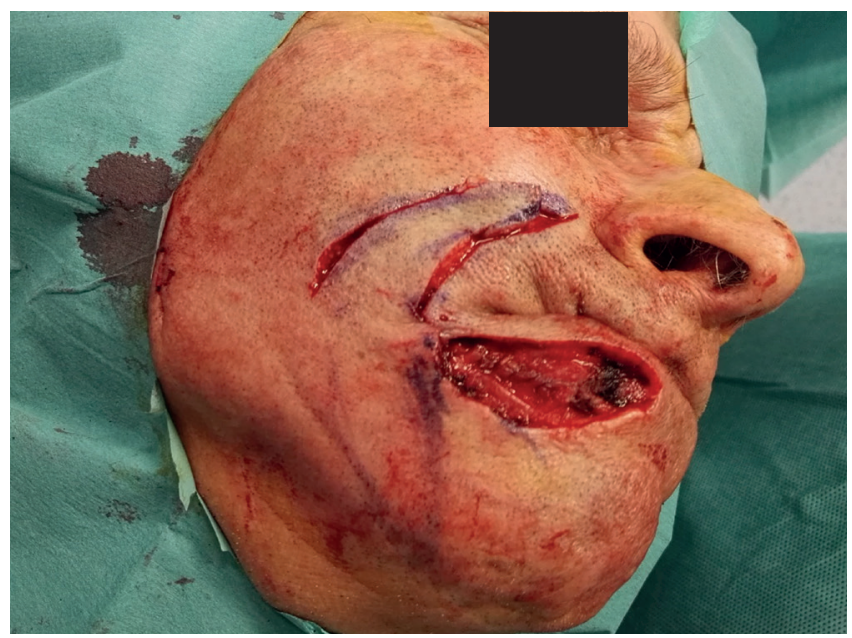

Figura 2 - Defeito cirúrgico elipsoide e retalho nasogeniano dissecado. 


\section{Pérolas Cirúrgicas}
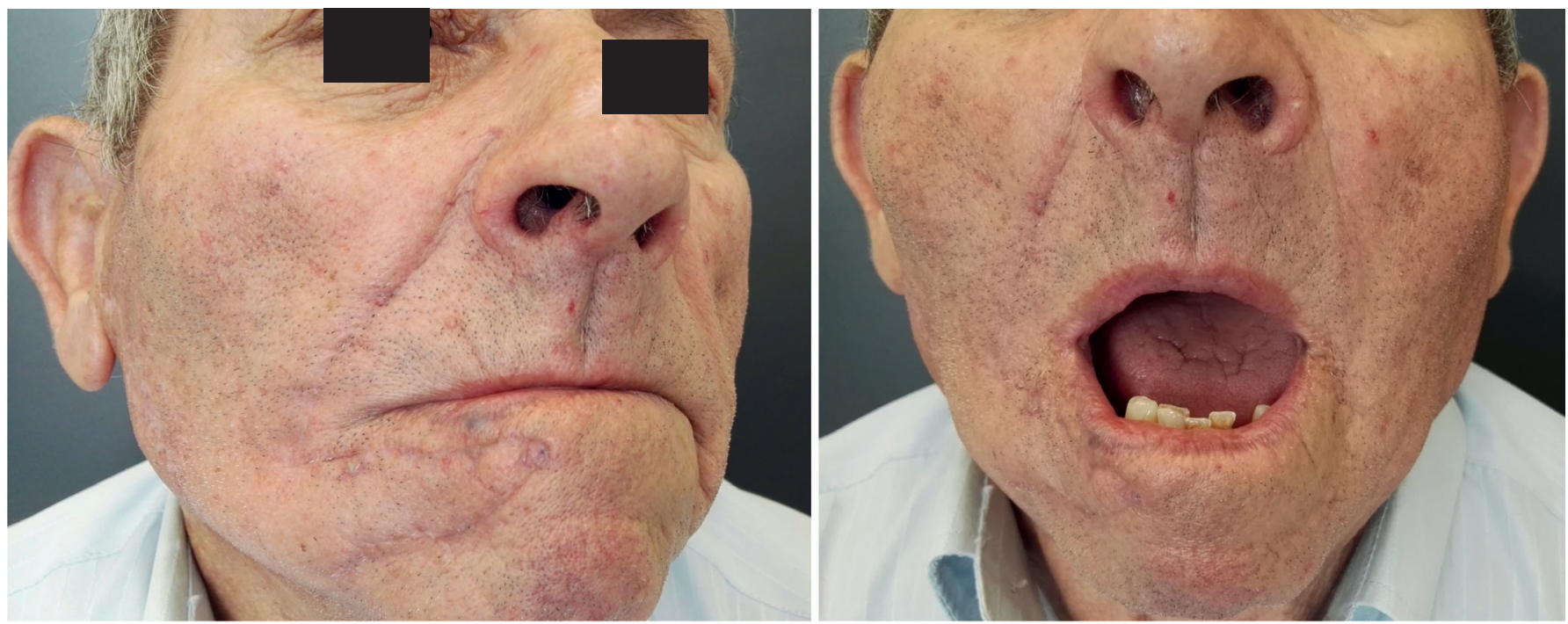

Figura 4 - Resultado estético aceitável dois meses depois, sem "orelha de cão", apagamento completo do sulco nasogeniano e limitação funcional.

Conflitos de interesse: Os autores declaram não possuir conflitos de interesse.

Suporte financeiro: $O$ presente trabalho não foi suportado por nenhum subsídio ou bolsa.

Confidencialidade dos dados: Os autores declaram ter seguido os protocolos do seu centro de trabalho acerca da publicação dos dados de doentes.

Protecção de pessoas e animais: Os autores declaram que os procedimentos seguidos estavam de acordo com os regulamentos estabelecidos pelos responsáveis da Comissão de Investigação Clínica e Ética e de acordo com a Declaração de Helsínquia da Associação Médica Mundial.

Consentimento dos Doentes: Obtido.

Conflicts of interest: The authors have no conflicts of interest to declare.

Financing Support: This work has not received any contribution, grant or scholarship.

Confidentiality of data: The authors declare that they have followed the protocols of their work center on the publication of data from patients.

Protection of human and animal subjects: The authors declare that the procedures followed were in accordance with the regulations of the relevant clinical research ethics committee and with those of the Code of Ethics of the World Medical Association (Declaration of Helsinki).

Patients consent: Obtained.

\section{REFERÊNCIAS}

1. Sousa H, Ferreira R, Almeida JR. Potencialidades do retalho nasogeniano. Rev Port ORL. 2006; 44: 129-34.

2. Andrade $P$, Brinca A, Vieira R, Figueiredo A. Double rhomboidal flap for reconstruction of large surgical defect of the labial commissure. An Bras Dermatol. 2012; 87:456-58.

3. Coutinho I, Ramos L, Gameiro AR, Vieira R, Figueiredo A. Lower lip reconstruction with nasolabial flap - going back to basics. An Bras Dermatol. 2015;90 (3 Suppl 1): S206-8.

4. Matos D, Goulão J. Retalho nasogeniano V-Y de avanço - duas variantes úteis na reconstrução nasal. Rev Soc Port Dermatol Venereol. 2014; 72: 525-29.

5. Matos D, Goulão J. Retalho nasogeniano de transposição com pedículo superior - princípios e aplicação fundamentais. Rev Soc Port Dermatol Venereol. 2014; 72: 513-23. 